\title{
Values, optimum stimulation levels and brand loyalty: new scales in new populations
}

\author{
Steven M. Burgess* \\ Department of Business Economics, University of the Witwatersrand, Johannesburg, Private Bag 3; P.O. Wits, 2050 Republic of South Africe \\ steve.burgess@pixie.co.za. \\ Mari Harris \\ Markinor (Pty) Ltd., P.O. Box 213, Pimegourie, 2123 Republic of South Africa
}

\begin{abstract}
The optimum stimulation level (OSL) and value priorities of 3493 South Africans were measured in the first administration of Steenkamp and Baumgartner's new shortened Change Seeker Index (CSI) and Schwartz' new Portraits Questionnaire $(\mathrm{PQ})$ in a nationally-representative developing nation sample. Both instruments performed well in a demanding crosscultural test as part of a syndicated research study. The results indicate that high and low OSL consumers exhibit value differences consistent with Schwartz theory about the content and structure of values suggesting that the shortened CSI may be tapping value differences. The predicted sinusoid pattern between value priorities and OSL also emerged. The association between values and brand loyalty exhibited three general sinusoid patterns. Comparative sample partitions based on value priorities and OSLs suggest that values may be sensitive to a wider range of motivations that underlie differences in exploratory product acquisition. shopping behaviour and brand loyalty. The results suggest that value priorities and OSL are important influences on brand loyalty behaviour.
\end{abstract}

\begin{abstract}
Waardes, optimum stimulasievlakke en handelsnaamlojaliteit: nuwe skale in nuwe bevolkings. Die optimum stimulasievlak (OSV) en waardevoorkeure van 3493 Suid-Afrikaners is in die eerste uitgawe van Steenkamp en Baumgartner se nuwe verkorte Change Seeker Index (CSI) en Schwartz se nuwe Portraits Questionnaire (PQ) in 'n nasionaal-verteenwoordigende steekproef in 'n ontwikkelende nasie gemeet. Albei toetsmetodes het goed gevaar in 'n veeleisende kruiskulturele toets wat deel was van 'n sindikaatnavorsingstudie. Die resultate toon dat hoë en lae OSV-verbruikers waardeverskille toon wat in ooreenstemming is met Schwartz se teorie oor die inhoud en struktuur van waardes. wat suggereer dat die verkorte CSI waardeverskille wel onderskep. Die verwagte sinuskromme tussen waardevoorkeure en OSV het ook na vore gekom. Die verbintenis tussen waardes en handelsnaamlojaliteit het drie algemene sinuskrommes getoon. Vergelykende steekproefverdelings, gebaseer op waardevoorkeure en OSVs, suggereer dat waardes vir 'n groter verskeidenheid motiverings gevoelig kan wees wat verskille in proefprodukverkryging, koopgedrag en handelsnaamlojaliteit ten grondslag lê. Die resultate toon dat waardevoorkeure en OSVS 'n belangrike invloed op handelsnaamlojaliteit het.
\end{abstract}

* Author to whom correspondence should be addressed.

\section{Introduction}

The new emphasis on relationships in marketing (e.g. Berry, 1995; Berry \& Gresham, 1986; Blattberg \& Deighton, 1991; Cravens, 1995; Hunt \& Morgan, 1994; Jüttner \& Wehrli, 1994; Payne, 1995; Peppers \& Rogers, 1993; Sheth \& Parvatiyar, 1995) has spurred a resurgence of interest in brand loyalty by scholarly and applied marketers. Brand loyalty has important implications for company profitability and longterm survival in addition to the obvious avoidance of new customer acquisition costs. According to Reichheld (1996), a $5 \%$ increase in customer retention can increase the net present value of an average customer's lifetime value by more than $75 \%$. Longer-term customers are less price-sensitive (Krishnamurthi \& Raj, 1991), provide new customer referrals (Cross \& Smith, 1995) and often require less service and operating support (Reichheld, 1996). The return of brand loyalty to the mainstream coincides with the emergence of a new digital environment characterised by discontinuity, technological upheaval and intensive information management capabilities (Tapscott, 1996). Astute companies have begun to place increasing importance on automated decision and support systems that facilitate greater organisational empathy with customers, aid cusiomer service and enhance profitability (Burgess, 1998: Peppers \& Rogers, 1997). The changing environment is one factor behind recent calls by influential scholarly researchers to identify new types and sources of affect that might comprise and distinguish loyalty responses, especially from a phenomenological perspective (i.e. Foumier \& Yao, 1997; Oliver, 1997). This article focuses on exploratory consumer behaviour (ECB), an often neglected influence on brand loyalty that has received almost no attention in the brand loyalty literature.

Risk-taking in product and retail outlet choice, innovative shopping behaviour, variety and novelty-seeking, browsing and recreational shopping and curiosity-motivated information processing are among the many consumer behaviours thought to have strong exploratory components (Baumgartner \& Steenkamp, 1996; McAlister \& Pessemier, 1982; Steenkamp \& Baumgartner, 1992). The tendency to engage in ECB has been operationalized most often using instruments designed to measure optimum stimulation level (OSL) (Baumgartner \& Steenkamp, 1996; Steenkamp \& Baumgartner, 1992). Although values and OSL have been the focus of large and important consumer research streams, these streams have rarely enriched each other and the role of values in ECB has not been explored. The current research contributes to the literature by exploring the conceptual and empirical links between values, OSL and brand loyalty and by proposing a new explanation for ECB based on value priority differences. It 
employs two new and reliable shortened scales for the first time to nationally-representative samples in a developing nation environment and extends values and OSL research to previously inaccessible populations at a time when influential researchers are calling for increased research in such economies (Cunningham \& Green, 1984: Monroe, 1993; Quelch \& Austin, 1993)

The remainder of this article is organised as follows. In the second section, we briefly review the literature concerning $\mathrm{OSL}$, values and exploratory consumer behaviour. We propose a set of hypotheses in the third section, based on the theoretical foundation presented in the previous section. The methodology in the fourth section is followed by our presentation of the results in the fifth. We finish in the sixth section with conclusions, managerial implications and suggestions for future research.

\section{Literature review}

Optimum stimulation level and exploratory consumer behaviour

Steenkamp \& Baumgartner (1995) propose that OSL is a personality trait affecting the extent to which people engage in ECB. First proposed by Hebb (1955) and Leuba (1955) over four decades ago, OSL has been the subject of many theoretical frameworks (e.g. Berlyne, 1960; Fiske \& Maddi, 1961; Fowler, 1965) that share the basic premise that an individual's preference function for stimulation in life is an inverted U-shaped curve with intermediate levels of stimulation being most preferred (see Sheth, Newman, \& Gross, 1991a; Steenkamp \& Baumgartner, 1992; Steenkamp, Baumgartner, \& Van der Wulp, 1996). Dogmatism, intolerance of ambiguity and rigidity have been identified as negative correlates to OSL (Raju, 1980).

OSL was first identified as an influence on ECB in the late 1960s by Howard \& Sheth (1969) and soon received interest from others (e.g. Hansen, 1972; Venkatesan, 1973). However, real progress began when focus shifted to the exploratory aspects of a more holistic range of purchase and consumption behaviours in the 1980s (e.g. Hirschman, 1980; 1984; Hirschman \& Holbrook, 1982; Holbrook \& Hirschman, 1982; Raju, 1981 ) and a range of studies linked high OSLs to preferences for environmental stimuli such as stimulation, discontinuity, novelty, complexity, incongruity, change and ambiguity (McAlister \& Pessemier, 1982; Raju, 1980; Zuckerman, 1979). Consumers seeking thrills, adventure, disinhibition, new experiences, escape from boredom, unfamiliarity and alternation among familiar things have been identified as engaging in consumer behaviours in order to raise their level of stimulation in life (Hirschman, 1980; McAlister \& Pessemier, 1982; Raju, 1980; 1981; Zuckerman, 1979). It follows that consumers engage in ECB, at least in part, in an effort to regulate their exposure to stimulation (Baumgartner \& Steenkamp, 1996). Contemporary interest in OSL has been stimulated most by Steenkamp \& Baumgartner's (Baumgartner \& Steenkamp, 1996; Steenkamp \& Baumgartner, 1992) efforts to integrate the ECB literature and develop operational tools for measuring OSL and the tendency to engage in ECB. Baumgartner \& Steenkamp (1996: 127) concluded that a significant correlation with measures of OSL is the 'most impor- tant criterion-related validity test for any scale purporting 10 assess exploratory buyer behaviour tendencies".

\section{Schwartz' theory of value content and structure}

The human values concept that informs the current research has emerged from a substantial literature. seminally influenced by psychologist Milton Rokeach (1973) but also by sociologists and anthropologists, that has linked personal values to most forms of consumer behaviour (Burgess, 1992: Kahle, 1990).' Rokeach's (1973) proposition, that values are 'enduring beliefs that a specific mode of conduct or end-state of existence is preferable to a converse mode of conduct or end-state of existence', was a major advance that brought what previously had been a vague and general concept into the research mainstream across the behavioural sciences. His influence on consumer research continues to be evident in the prevailing assumptions that values guide consumer behaviour in concert with attitudes and other beliefs, that consumer behaviours can be traced to diversity in the relative importance consumers attach to a comparatively limited number of values common to all people, that the value system is an important key to understanding human behaviour and that values are relatively enduring.

Richins \& Dawson (1992) recently noted the slowing of scholarly consumer research concerning values in the $1990 \mathrm{~s}$ but the research of psychologist Shalom Schwartz has gained much influence and resulted in a stream of values research elsewhere. Schwartz $(1992 ; 1994 ; 1997)$ has refined the values concept, proposed a theory of the universal content and structure of human values, designed instruments to test the theory and reported consistently supportive results in tests of more than 100,000 respondents in more than 60 countries According to Schwartz, values are transituational goals that vary in importance and serve as guiding principles in life Perhaps his greatest contribution has been to derive a typology of ten motivational values based on three universal requirements of human existence to which all individuals and societies must be responsive: the needs of individuals as biological organisms, the requisites of co-ordinated social interaction and the survival and welfare needs of groups. His research in a wide range of cultures on every inhabited continent presents convincing evidence supporting his theory of value contents and structure while calling into question the existence of Rokeach's (1973) terminal and instrumental value concepts and Rokeach's (1973) preliminary attempts to further refine these two value types (Schwartz, Roccas \& Sagiv, 1992; Schwartz, 1994; Schwartz, Lehmann, Melech, Burgess \& Harris, 1998). The results of his impressive programmatic approach to defining value content and structure make it possible to conceive of people's value systems as integrated structures of motivations that share universal elements across cultures. Thus, his theory provides a reliable platform for generating hypotheses relating value priorities to other constructs within and across cultures.

Table I outlines Schwartz' ten motivational value types and the individual values typically included in the content of each The value types, distinguished by the motivational goals each expresses, form a continuum of related motivations at a more basic level that give rise to a circumplex, the circular structure depicted in Figure 1. Schwartz (1994: 25) notes that the 
Table 1 Definitions of the ten motivational value types in terms of their goals and specific values that re-present them

\begin{tabular}{|c|c|c|}
\hline Value type. & Detinition & Exemplary values \\
\hline Power & Social status and prestige, control or dominance over people and resources & Social power, authority, wealth \\
\hline Achieverment & Personal success through demonstrating competence according to social standards & Successful, capable, ambitious \\
\hline Hedonism & Pleasure and sensuous gratification for oneself & Pleasure, enjoying life \\
\hline Stimulation & Excitement, novelty and change in life & Daring, varied life, an exciting life \\
\hline Self-direction & Independent thought and action-choosing, creating, exploring & Creativity, curious, freedom \\
\hline Universalism & $\begin{array}{l}\text { Understanding, appreciation, tolerance and protection for the welfare of all } \\
\text { people and for nature }\end{array}$ & $\begin{array}{l}\text { Broadminded, social justice, equality, protecting the en- } \\
\text { vironment }\end{array}$ \\
\hline Benevolence & $\begin{array}{l}\text { Preservation and enhancement of the welfare of people with whom one is in fre- } \\
\text { quent personal contact }\end{array}$ & Heipful, honest, forgiving \\
\hline Tradition & $\begin{array}{l}\text { Respect. commitment, and acceptance of the customs and ideas that traditional } \\
\text { culture or religion provide }\end{array}$ & Humble, devout, accepting my portion in life \\
\hline Conformin & $\begin{array}{l}\text { Restraint of actions, inclinations and impulses likely to upset or harm others } \\
\text { and violate social expectations or norms }\end{array}$ & Politeness, obedient. honouring one's parents or elders \\
\hline Security & Safety, harmony and stability of society, of relationships, and of self & Social order, clean \\
\hline
\end{tabular}

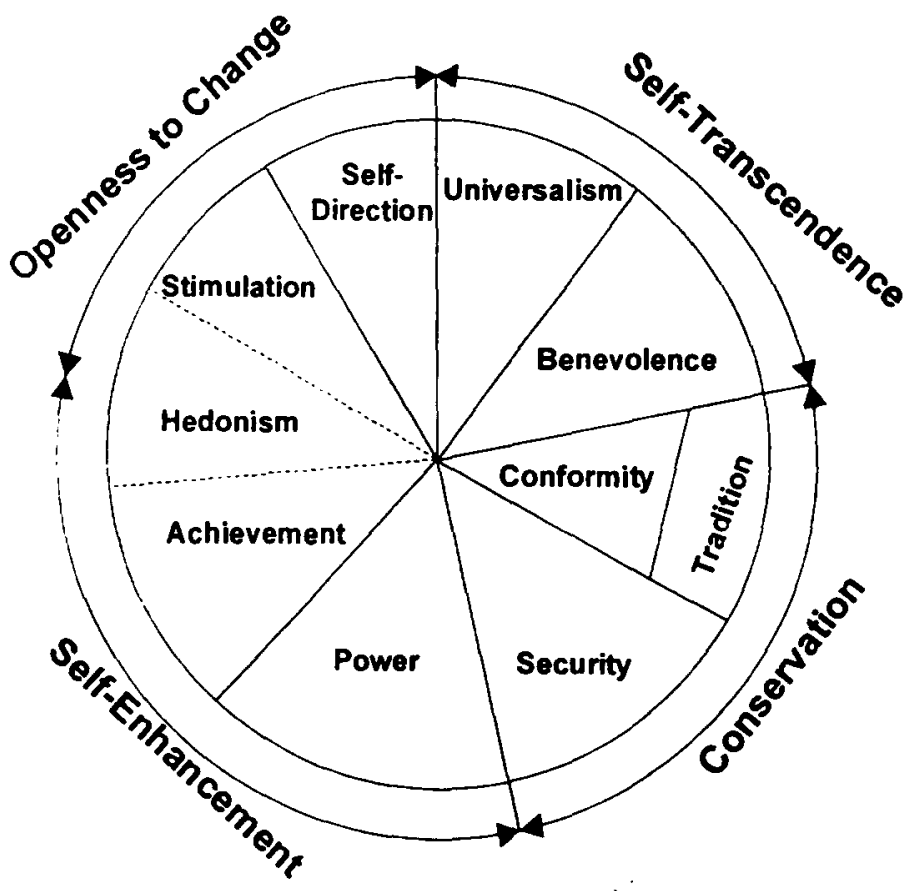

Figure 1 Structural relations of the motivational value types in Schwartz' model (source: Schwartz et al., 1994)

boundaries of the value types in the circumplex structure are 'fuzzy' and that partitioning the individual values into motivational value types is a convenient decision about where one value type begins and another ends. The ten motivational value types can be arranged along two bipolar higher-order dimensions appearing at the periphery of the associated value types in Figure $1:$ (1) openness to change versus conservation and (2) self-enhancement versus self-transcendence. These four poles constitute higher-order value types in the theory.

The theory proposes dynamic relations between the ten value types. An individual's pursuit of one value type will have practical, social and psychological consequences that are compatible or in conflict with other value types. Adjacent value types are most compatible. Conflict increases in proportion to the distance between value types with value types in opposing positions from the centre of the structure in greatest competition. For example, seeking novelty (a stimulation value) by visiting a new fashion-clothing outlet may be compatible with the pursuit of curiosity (a self-direction value) but in conflict with compliance with social norms (a conformity value). Seeking pleasure (a hedonism value) by visiting an unfamiliar restaurant may be compatible with the pursuit of a varied life (a stimulation value) but in conflict with adherence to the dietary restrictions of one's religion (a tradition value).

\section{Current research}

The preceding paragraph illustrates how behaviours with strong exploratory components may be compatible with the pursuit of stimulation, hedonism and self-direction values and in conflict with tradition and conformity values. Thus, atthough it has been proposed that ECB need not be purposeful (Holbrook \& Hirschman, 1982) and that its reward may be intrinsic (Maddi, 1961), the theory suggests an alternative phenomenological approach to understanding ECB; namely, that consumers may choose to engage or avoid ECBs due to the relative priority they place on values within the framework of an integrated value system. The following sections draw on the literature to propose hypotheses concerning (1) the value priorities of high and low OSL consumers, (2) the pattern of association between values and OSL, (3) the brand loyalty of high and low OSL consumers and (4) the pattern of association between values and brand loyalty.

\section{Value priorities of high and low OSL consumers}

Although there is little previous research concerning values and $E C B$, value priorities often can be inferred from personality trait research (see Bilsky \& Schwartz, 1994; Burgess, 1992; Rokeach, 1973). Thus, previous research concerning OSL and related constructs may inform us concerning the value priorities of high and low OSL consumers. The following discussion examines previous OSL research in the context of Schwartz' theory. 
(Ipenness to chamge versus conservation

Conservation values oppose openness to change values on one higher-order bipolar dimension in the values theory (namely, values with an emphasis on conformity with the group, maintenance of traditions and submissive selfrestriction iersus values favouring change and independent thought and action). Steenkamp, Ter Hofstede \& Wedel (in press) recently found that consumer innovativeness declines as consumers place more priority on conservation values and rises with priority on openness to change values.

\section{- Conformin and tradition values}

According to the values theory, conformity and tradition values entail the subordination of the self in favour of the group. Conformity values are distinguished by the restraint of behaviours likely to upset or harm others or violate social norms. Tradition values have the goal of respect. commitment and acceptance of the customs, ideas and symbols imposed on one by cultural or religious forces (Schwartz et al., 1992). Zuckerman (1979) proposed that high OSL consumers, as identified by his Sensation-Seeking Scale, are non-conformists who are more likely to place their own needs above social convention; implying less priority for conformity and tradition values. $\mathrm{Hl}$ :High (OSL consumers will place less priority on con-

formity and tradition values than low OSL consumers.

- Stimulation and self-direction values

Stimulation and self-direction involve intrinsic interest in novelty and mastery (Schwartz, 1994). Schwartz (1992) argues that 'stimulation values derive from the presumed organismic need for variety and stimulation in order to maintain an optimal level of activation'. The motivational goal of stimulation is excitement, novelty and challenge in life. Choosing, creating and exploring through independent thought and action characterise self-direction. Raju (1981) suggested that high OSL consumers were more curious. Zuckerman (1979) concluded that high sensation seekers were more independent. Thus, stimulation values may derive from OSL and should correlate highly with any measure of it, at the very least. Steenkamp et al. (1996) found that, the larger the discrepancy between an individual's current and optimum levels of stimulation, the more that advertising stimuli aroused the individual.

$\mathrm{H} 2$ :High OSL consumers will place more priority on stimulation and self-direction values than low OSL consumers.

\section{Hedonism}

Zuckerman's (1979) findings concerning non-conformity also imply that consumers with high OSLs will place greater priority on hedonism, self-direction and stimulation values. Hedonism has emerged as a motivational value type that serves higher-order openness to change and self-enhancement goals in different samples, according to Schwartz (1994). Hedonism and stimulation share a desire for affectively pleasant arousal while hedonism and achievement share a desire for self-centred satisfaction (Schwartz, 1994). High sensation-seekers are characterised by a lifestyle that emphasises hedonistic self-fulfilment (Zuckerman, 1979).

H3: High OSL consumers will place more priority on hedonism values than low OSL consumers.

\section{Self-enhancement versus self-transcendence}

The second higher-order bipolar dimension contrasts selfenhancement values with self-transcendence values; that is. values that motivate people to serve their own interests even at the expense of others and nature versus values that motivate people to serve the interests of others, close and distant and of nature even if it is at their own expense (Schwartz, 1992). According to the theory, the correlation of OSL with self-enhancement or self-transcendence values should be lower than correlations with openness to change or conservation values.

\section{Universalism, benevolence and security}

Although universalism and benevolence are concerned with the enhancement of others and the transcendence of the self, these two motivational value types differ in their motivation for self-transcendence and their degree of compatibility with other value types. The motivational goal of universalism is the tolerance, appreciation, understanding, concern and protection for the welfare of all others and of nature. Like self-direction, universalism expresses one's reliance on personal judgement and comfort with diversity of existence (Schwartz, 1994). This contrasts with the much narrower motivational goal of benevolence, which is concerned with the enhancement of people with whom one is in frequent contact, such as family, friends and important others. Unlike universalism, benevolence emphasises devotion to one's in-group, as is the case with tradition. The theory suggests the correlation of OSL with these two values will be less extreme than the correlations with openness to change and conservation values and suggests that it will be negative. This is consistent with the findings of previous OSL research. Drawing conclusions from the correlations of OSL (as measured using Mehrabian \& Russell's [1974] Arousal Seeking Tendency scale) with intolerance of ambiguity, rigidity and dogmatism, Raju (1981: 276) concluded that high and low OSL consumers did not differ as regards their open-mindedness 'but because of other reasons such as risk avoidance'. Broadminded and open-minded are universalism values that constitute a single scale item in the Rokeach Value Survey (Rokeach, 1973). Nonetheless, the emphasis these two values place on others, instead of the self, suggests that low OSL respondents will place greater priority on them.

Although the theory suggests that security values serve higher-order conservation value goals, a smallest space analysis (SSA) of the data revealed that security emerged in a mixed region with benevolence and universalism for black respondents who had completed six years of formal schooling (see Schwartz et al., 1998). Thus, the results of the SSA suggest instead that security is serving self-transcendence goals in the current research. This has been reported previously concerning African values research (e.g. Schwartz et al., 1998) and suggests that security may have a meaning somewhat different to that postulated by the theory in the region. If security has a meaning more consistent with conservation, then we would expect consumers with high OSLs to place less importance on it. However, in either case, we would expect consumers with low OSLs to place higher priority on this value than high 
OSL respondents. Luckerman's (1979) observation that high sensation-sechers were more likely to place their own needs above the needs of others also suggests a low priority for security values.

H4: High OSL consumers will place less priority on uni-

versalism. benevolence and security values than low

OSL consumers nall

Achievement and power

Achievement and power emphasise power over others, social superiority and esteem. Whereas the motivational goal of achievement is social approval gained by demonstrating competence within the context of social and cultural standards, power emphasises the attainment of control or dominance over others and resources and the attainment of prestige and recognised social status. The theory suggests a moderate positive correlation of these values with OSL. Zuckerman"s (1979) sensation-seeking observations are supporive. suggesting that high OSL consumers maintain their autonomy through assertiveness in relationships $w$ ith others rather than through isolation

HS:High (JSL consumers will place moderately more priority on achievement and power values than low OSL consumers.

\section{Pattern of association between values and $\mathrm{OSL}$}

i he preceding review draw s attention to a more global aspect of Schwartz theory. The nature of the proposed dynamic - elations between the value types in Schwartz' theory suggests that a regular pattern of associations. in the form of a sinusoid curve (Schwartz et al. 1992). will emerge when any external consumer characteristic is associated with the value ispes. Although ECB is not the only reason why consumers witch brands or buy more brands, it should be a significant nfluence based on the previous discussion. Thus, a sinusoid curve of associations between value priorities and OSL should demonstrate the characteristics identified in hypothesis 6.

H6: The correlations between value priorities and OSL will produce a sinusoid curve characterised by positive correlations with power. achievement, self-direction, hedonism and stimulation and negative correlations with universalism. benevolence, security; tradition and conformity.

\section{Brand loyalty of high and low.OSL consumers}

Despite more than 70 years of investigation. brand loyalty is a much ignored construct enjoying renewed interest. Recent work has attempted to reconceptualize the nature and content of brand lovalty and make distinctions between situational and proactive loyalty (e.g. Fournier \& Yao, 1997; Oliver, 1997). Oliver's recent definition of loyalty as

-...a deeply-held predisposition to rebuy or repatronize a preferred brand or service consistently in the future. despue (original emphasis) situational influences and marketing efforts having the potential to cause switching behaviour' (1997: 392)

voices the essence of a growing consensus. Loyalty can be thought of as stemming from cognition about brands and affect toward them that informs a conative loyalty to the brand characterised b! a deeply-held commitment that takes on motivational properties leading to action. Oliver (1997) has proposed that these types of loyalty - cognitive, affective, conative and action - are phases in a progression to ultimate brand loyalty; however, much work remains to be done to validate the proposed progression and understand the links between the various phases. Although not focused on brand loyalty, efforts by Bagozzi and his colleagues (Bagozzi \& Kimmel, 1995; Bagozzi \& Warshaw, 1990) to understand the link between conation and action in the context of goaldirected behaviour is indicative of the type of work required in this area.

Baumgartner \& Steenkamp (1996) recently linked OSL to exploratory acquisition of products (EAP) and exploratory information processing (EIP). A significant portion of total brand usage by consumers with high stimulation preferences is thought to occur as a result of EAP and this has important implications for every phase of their brand loyalty. EIP may lead these consumers to be more attentive to the environment, resulting in more information acquisition about brands and lower cognitive loyalty. Higher stimulation preferences may lead to an unrecognised general state of dissatisfaction that leads to misperceived feelings of dissatisfaction with most brands, or a preference for multi-brand usage that lowers affective loyalty. Lowered rognitive or affective loyalty may lead to brand promiscuity that diminishes the perceived commitment to a brand required for conative consistency. The tendency to prefer stimulation may predispose one to avoid the inertia a d momentum characteristic of true action loyalty. ECB, $v$ lues and OSL have not played a meaningful role in the scho. rly academic (compare Dick \& Basu, 1994; Fournier \& Yao, 1997; Oliver. 1997) or applied (compare Cross \& Smith, 1995: Peppers \& Rogers, 1993: 1997; Reichheld, 1996) loyalty literature. despite the obvious implications for brand loyalty. The current research focuses on the link between a possible predisposition to affective disloyalty (preference for stimulation) and the outcome of action disloyalty (brand usage).

H7:Respondents with high stimulation preferences will report using more brands than those with low stimulation preferences.

\section{Pattern of association between values and brand loyalty}

Burgess (1992) recently called attention to lack of progress in understanding how values are activated and the process by which values become influential during consumer decision making. The range of products chosen for the current research are germane to the investigation of two issues raised by Burgess: the relationship (1) between values and problem solving and (2) between values and hedonic/utilitarian brand positions. The notion that consumers process more information and process it more deeply during extended problem solving has been an important aspect of the major consumer behaviour metatheories (Engel. Blackwell \& Miniard, 1995; Howard \& Sheth, 1969). Although little is known about the relationship between values and problem solving, one could surmise that values would be more likely to be influential when consumers are pursuing extended problem solving (EPS) or that different values might be activated during different types of problem solving. Similarly, the purest forms 
of hedonic and utilitarian product positioning may be likely to activate different types of values.

Cigarettes and alcoholic beverages are product categories characterised by many similarities. By their nature, these products entail a certain amount of risk that increases proportionally with the amount consumed - a risk not only to one's physical health and well-being but also to the health and wellbeing of others and to one's relationships with others. The risk of addiction to alcoholic beverages and cigarettes also is well known. Brands in both product categories often are positioned on hedonic benefits portrayed through associations with sports, nightlife, overseas travel and other stimulating lifestyle cues. We expect that openness to change values should correlate positively and conservation values negatively, with the number of brands used in these categories. Over-the-counter (OTC) non-prescription medications represent a very different product category type. OTC medications commonly are positioned on utilitarian benefits associated with pain and symptom relief. Consumers may become more involved (Laurent \& Kapferer, 1986) when contemplating OTC medication purchases and thus pursue more extended problem solving, because illness threatens the physical being and security of the self or an important other. Many OTC medications, such as Eno, Grandpa`s Headache Powders or Lennon's traditional Dutch remedies, have enjoyed success for generations while impressive overseas success stories such as Johnson \& Johnson's Tylenol paracetamol have failed when launched into the South African market. Trust is a common element in many brand positions. Recognising that people use OTC medications to avoid risk of more serious illness. we expect conservation values to be most positively correlated and openness to change values to be most negatively correlated with number of brands used

The first two patterns of association are consistent with the expectations of OSL theory. However, it also is possible to conceive of situations in which consumers are disloyal for reasons related to value priorities that are inconsistent with OSL theory. For instance, motor cars, banks, food products, soft drinks and major food and clothing retailers are examples of products characterised by mid-range problem solving (MPS) behaviours. ${ }^{2}$ Brand positions, such as Land Rover's 'the best $4 \times 4 \times$ far' (status and durability) or Pick 'n Pay's 'don't pay more, come get more' (competence, family security and low prices), often associate brands with hedonic and utilitarian benefits coincidentally. OSL theory implies that consumers in any product category who place higher priority on openness to change values would be more disloyal and conversely, that those who place higher priority on tradition and conformity would be more loyal. However, priorities on values such as achievement (buying the latest computer software to demonstrate competence and mastery), power (buying exclusive fashion wear or motor cars to demonstrate personal success and status), benevolence (subordinating one's own dietary preferences in order to share food products that appeal to the tastes of family and friends) or universalism (changing to the most ecologically-friendly brands) clearly can serve as a rationale for loyalty behaviour. Thus, for these product categories, the theory gives no reason to expect openness to change or conservation values to be any more strongly associated with brand loyalty than self-transcendence and selt-enhancement values.

H8:The correlations between measures of acturn lovaln and value priorities will produce a simsord curve characterised by (a) negative correlations whit conformity and radition and positive correlations with stimulation. selfdirection and hedonism for cigarettes and alcoholic hererages; (b) positive correlations with conformity and radition and negative correlations with stimulation. selfdirection and hedonism for OTC non-prescription medications and (c) no special pattern of correlation for openness to change or conservation values for motor cars. banks, food products, soft drinks and major food and clothing retailers

\section{Method}

A leading professional marketing research company administered the Short Form CSI and a new values scale, the Portraits Questionnaire (Schwartz, Lehmann \& Roccas, in press), to a representative national sample of 3493 South Africans that included 165 Asians, 2000 Blacks, 390 Coloureds and 938 Whites. The instruments were translated into Afrikaans, English, North Sotho, South Sotho, Venda, Tswana, Xhosa and Zulu using accepted questionnaire design and back-translation techniques (Brislin, 1986: Brislin. Lonner \& Thorndike, 1973; Lonner \& Berry, 1986). Respondents provided information concerning demographic characteristics, financial services products used and brands ever used and brands regularly used now in the following product categories: alcoholic drinks, motor cars/automobiles, banks, cigarettes, food products, major retailers, soft drinks, selected nonprescription medications and petroleum/gasoline station retail brands.

\section{Using shortened scales in ECM environments}

The respondents in the current research are less educated than any sample to which the SVS was administered and less than two-thirds completed high school. Limited literacy and numeracy skills are among the special threats to reliability and validity in emerging consumer market (ECM) research that require careful consideration (Brislin. 1986; Brislin et al. 1973; Lonner \& Berry, 1986). Brief scales such as the shortened CSI and PQ scales seem especially appropriate for ECM environments because they reduce cognitive demands on respondents and shorten interview completion time. These are important benefits in any environment when the cognitive and temporal demands of longer scales might threaten the broader reliability and validity of a research project (such as in syndicated marketing research projects or in research with adolescent or elderly target populations), when respondents have limited human development (especially limited literacy and numeracy skills), or when budgetary constraints preclude the use of longer scales. However, researchers must carefully consider certain challenges posed by shortened scales before use. For instance, the failure to include sufficient indicator items per latent construct may lead to identification problems (see Bollen, 1989) that preclude structural equation modelling with important implications for the ability to choose a model that is sufficiently disaggregated (see Bagozzi \& Edwards. 1998; Bagozzi \& Kimmel, 1995) to specify and test for the 
multidimensionality of personality constructs or for measurement invariance across cultures (see Steenkamp \& Baumgartner. in press). The current research provides a particularly rigorous. but typical, test for the two new scales in an applied $E C W$ research environment. The shortened CSI and PQ icales wete administered within a large. syndicated survey questionnaite and respondents had already been responding to the surve about twenty minutes on average when they encountered the two scales.

Respondents who failed to respond or responded 'don $t$ know to a simulus item on either the PQ or CSI scale 1320 respondents. $9.2 \%$ of the sample), provided the same response for every nem in the 7-item CSI scale including the nezatively scored items $(46.1 .3 \%)$. or consecutively provided the same response for 15 or more items on the PO scale 113 . $0.2 \%$ ) were deemed to have failed to respond to the survey letther because they failed to understand the entire scale or because of response set) and were not included in the analyses. According to these criteria. $370(10.6 \%)$ respondents were dropped. When compared to the overall sample, the dropped respondents were somewhat more likely to be Black $(68.4 \%$ versus $57.3 \%$ of the total sample) and to have not completed high school (71.90\% versus $64.3 \%$ ) but the associatıon between being dropped and race or education was not strong in either instance (Cramer's $\mathrm{V}<.080)$.

\section{I)SL}

(If the four major scales used most often in measuring OSL. Sieenkamp \& Baumgartner (1992) propose that Garlington and Shimota s (1964) 95-item Change Seeker Index (CSI) is the preferred instrument

based on both the magnitude of loadings of the sum-

mated scale scores on the underlying construct of OSL

in a confirmatory factor analysis and signific?nt relationships with related constructs across a series of seven consumer behavior experiments'.

Steenkamp \& Baumgartner (1995) recently developed a new shortened form of the CSI and validated it cross-culturally in Belgium. the Netherlands and the USA. The results suggest that the shortened scale may have improved nomological validity and psychometric properties but the scale requires more extensive cross-cultural validation and translation into other languages before firmer conclusions may be drawn (Steenkamp \& Baumgartner, 1995). Reliabilities for the two negative items of the shortened CSI were not acceptable. However, once the two negative items were dropped from the CSI scale, both instruments performed well with acceptable coefficient alpha reliabilities, especially when considering the low education levels of the respondents. ${ }^{3}$

\section{Values}

Previous South African research with the Schwartz Value Survey (SVS) (Schwartz et al, 1992) had suggested support for Schwartz values theory (Burgess et al., 1994). However, other research using the SVS had suggested that Schwartz' values theory may not fit the value systems of the young, the less educated. the elderly and the illiterate as well as those from Black African, Indian, Malaysian and rural cultures in I:CMs - groups that typicall! may find the SVS too abstract (Schwartz \& Bardi, 1997). In response, Schwartz et al (in press) recently developed $P Q$ to assess value priorities in such populations. Table $A \mathrm{l}$ in the Appendix presents $P Q$ and its instruction set. The $P Q$ and the SVS measure the same motivational value types but differ significantly in terms of measurement approach. The SVS asks respondents to rate the importance of 57 values as guiding principles in one's life while $P Q$ requests a similarity judgement comparing 29 brief textual 'portraits' of persons to one's self. The SVS presents abstract, context-free values while PQ presents people who are portrayed in terms of their goals. aspirations and wishes. SVS uses a nine-point numerical response scale while the $P Q$ uses six labelled check boxes. SVS respondents typically report that completing the scale requires seriots deliberation while $P Q$ respondents typically complete the scale in eight to ten minutes. The brief portraits included in the $P Q$ scale (Schwartz et al., in press) present respondents with descriptions of 29 different people. such as 'She seeks surprises and is always looking for new things to do. She thinks it is important to do lots of different things in life . Schwartz calls attention to the nature of the similarity judgement of each textual portrait to the self (Schwartz et al., 1998, in press) This is important because studies reveal that similarity judgements are influenced by the direction of the comparison (e.g. Holyoake \& Gordon, 1983; Srull \& Gaelik. 1983: Tversky, 1977); with less salient stimuli (e.g. other people) perceived as more similar to salient stimuli (e.g. the self) than vice-versa.

Demographic characteristics, such as age, education. ethnicity. household income and gender have been linked to differences in value priorities using a host of instruments (Kahle \& Timmer, 1984; Pitts \& Woodside, 1984: Rokeach, 1973: Sheth et al., 1991b). Gender, age. household income, education, degree of urbanisation, marital status and ethnic cultural group emerged as value antecedents in the current research. Otherwise, values as measured by PQ have not yet been related meaningfully to attitudes, behaviour or background variables, as has been found with the SVS (Schwartz et al.. in press). As shown, value priorities generally differ between four traditional race groups and by gender. However. the

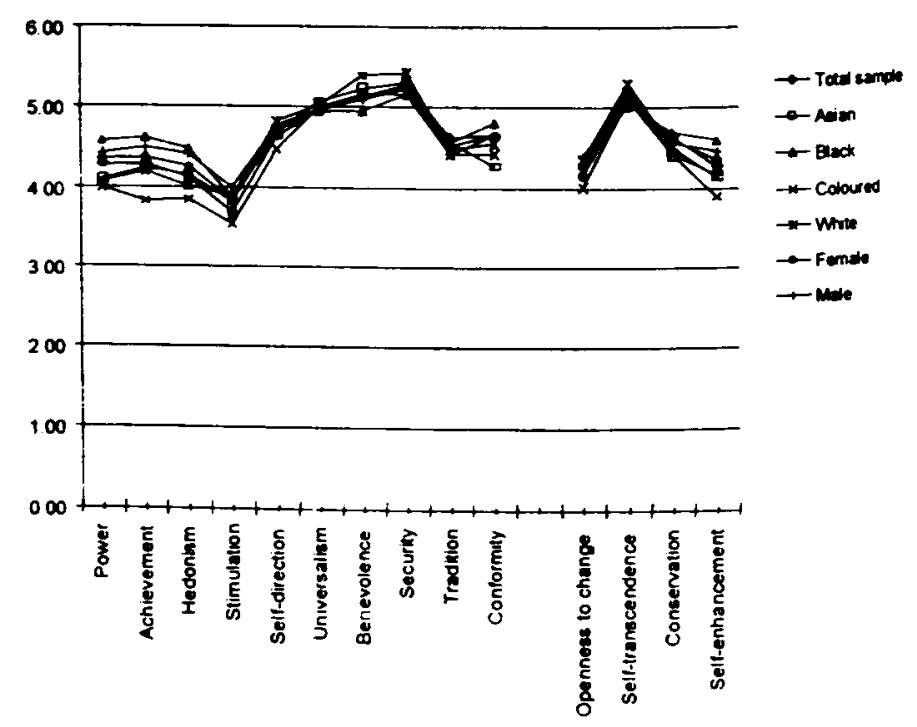

Figure 2 Mean importance of motivational value types by ethnic group and gender 
rankings of the mean similarity ratings demonstrate the remarkable relative importance of the value types across race and gender, as shown in Figure 2. The results for PQ in the current research suggest a surprising level of reliability given the education levels of the respondents and the multidimensionality of the scale. ${ }^{5}$

\section{- Definng high and low ()SL groups}

Three models of high, medium and low OSL respondents were defined using summated scores and cluster analysis. In Model A, respondents were ranked according to their summated five-item CSI scores and then grouped within the top two, middle four and bottom two deciles respectively (breaks in CSI score overlapped the decile boundaries and the final sample for the current research consisted of 746 high OSL consumers and 630 low OSL consumers). A two-step cluster analysis procedure was performed in the remaining models. First. the validity of a three-cluster solution was investigated by performing a Ward's minimum variance method cluster analysis. Ward's method was chosen because of its superior performance in recovering cluster structure (Milligan, 1981; Milligan \& Cooper, 1987). Although other criteria were inconclusive, the pseudo $t^{2}$ statistic (Duda \& Hart, 1973) suggested a three-cluster solution when applied to all remaining models. As the objective was to partition respondents into non-overlapping clusters, $\mathrm{K}$-means cluster analysis was chosen for the second step because of its demonstrated superiority (Milligan, 1981; Milligan \& Cooper, 1987). Model B respondents were clustered based on their ratings for the five CSI scale items. High and low OSL clusters were identified based on their mean OSL summated scores. Model $\mathrm{C}$ respondents were clustered on the $12 \mathrm{PQ}$ scale items measuring the stimulation, self-direction, tradition and conformity value types. High and low OSL clusters were identified based on the hypothesised value priorities predicted by the theory.

Schwartz (1996) has proposed that much is to be gained from understanding behaviour from the perspective of the value system - a value system in which the association of a behaviour with one value type has important implications for associations with other value types within an integrated structure of nearly universal motivational types. Thus, a fourth model (Model D) was conceived in which individuals were clustered on their priorities for the ten motivational value types using the same two-step procedure. Three groups were chosen because of the expectation that three types of association would occur between values and brand loyalty and also to facilitate comparisons with the results of Models A, B and c.

Table $\mathrm{A} 3$ in the Appendix reports selected characteristics for the various models. Models A, B and C produce high, medium and low stimulation groups with similar gender, race, age and monthly household income ( $\mathrm{HHI})$. Generally, the people within the high stimulation preference groups are more likely to be male, black and enjoying a higher monthly $\mathrm{HHI}$ than people within the low stimulation groups for these three models. Age and household income are subject to large standard deviations for all models. Model D Group 1 individuals are more likely to be male; Asian, Coloured, or White; older; and higher income than other groups in that model. Ad- ditional analysis shows that the three groups of consumers in each model include people from all household income strata."

\section{EAP and brand loyalty}

The nine consumer product categories studied in the current research include a range of consumer products typical of EPS and LPS product categories and include brands available in South Africa throughout the anti-apartheid sanctions and post-sanctions era. Two variables were selected as crude indicators of action loyalty in the nine product categories. First, respondents reported the number of brands ever used by selecting from a comprehensive list of brands. Then respondents reported the brands regularly used now from the list. Admittedly, both measures have limitations; for instance. age and household income obviously influence both. Although OSL is strongly correlated with the tendency to engage in ECB (Baumgartner \& Steenkamp, 1996), consumers with high ECB tendencies ultimately may not be able to act on them because of inadequate economic resources, inability to understand complex brand positioning concepts or physical access to alternatives. Nevertheless, although consumer self-reports of brands ever used and brands regularly used now are more crude than direct observation in the laboratory, such reports are a valuable indicator of action loyalty.

\section{Results}

\section{Value priorities of high and low OSL consumers}

The first set of hypotheses concerned the value priorities of respondents with high, medium and low stimulation preferences. These hypotheses were presented in relation to the two bipolar higher-order dimensions. Table 2 reports the mean brands ever used, brands regularly used now, OSL, mean value importance and the mean importance of values across the ten motivational value types and the four higher order dimensions for high, medium and low OSL respondents within Models A, B and C. Value importance was standardised within respondents for each motivational value type (by subtracting the mean rating of the $29 \mathrm{PQ}$ values from each value and then constructing an index for each motivational value type from the items according to the theory) because of the previously noted scale use effect (see the discussion about scale use effects in Schwartz et al.. 1992). Whether respondents are grouped according to CSI summated scores or are clustered using CSI ratings or PQ value priorities, respondents with high and low stimulation preferences exhibited the value priorities predicted in hypotheses 1 to 5: High OSL respondents placed higher relative priority on self-direction, stimulation, hedonism and achievement value types and on the higher-order openness to change and self-enhancement value types. Low OSL respondents placed higher relative priority on conformity, tradition. security, benevolence and universalism value types and on higher-order conservation and self-transcendence value types. Although a statistically insignificant result was observed for power values in Models A and B, the difference is in the hypothesised direction.

Model A performs best in terms of identifying respondents with high and low OSL scores. Nevertheless, Models A. B and $C$ all identify a respondent group with high stimulation 
association was hypothesised to be a sinusoid curve for all product categories, three different patterns were predicted: (1) negative correlations with conformity and tradition and positive correlations with stimulation, self-direction and hedonisin for cigarettes and alcoholic beverages: (2) positive correlations with conformity and tradition and negative correlations with stimulation, self-direction and hedonism for OTC non-prescription medications and (3) no special pattem of correlation for openness to change or conservation values for motor cars, banks. food products, soft drinks and major food and clothing retailers. The results show that three different patterns of association emerged from the correlation analysis (see Table 3 and Figures 4 and 5 ).

\section{Alcoholic beverages and cigaretles}

Action disloyalty for cigarettes and alcoholic beverages correlated most positively with openness to change values and most negatively with conservation values, as hypothesised. In both product categories, the correlation with universalism is less positive than with self-direction and benevolence; the small dip representing a small departure from the predicted sinusoid pattern of relations. Schwartz (Schwartz et al., 1992; Schwartz, 1994) reports that it is not unusual to observe SSAs with mixed regions and reversals of order in the value structure. Universalism, benevolence and security emerged as a mixed region in the SSA of black respondents values in the current research. When these three regions are considered as a

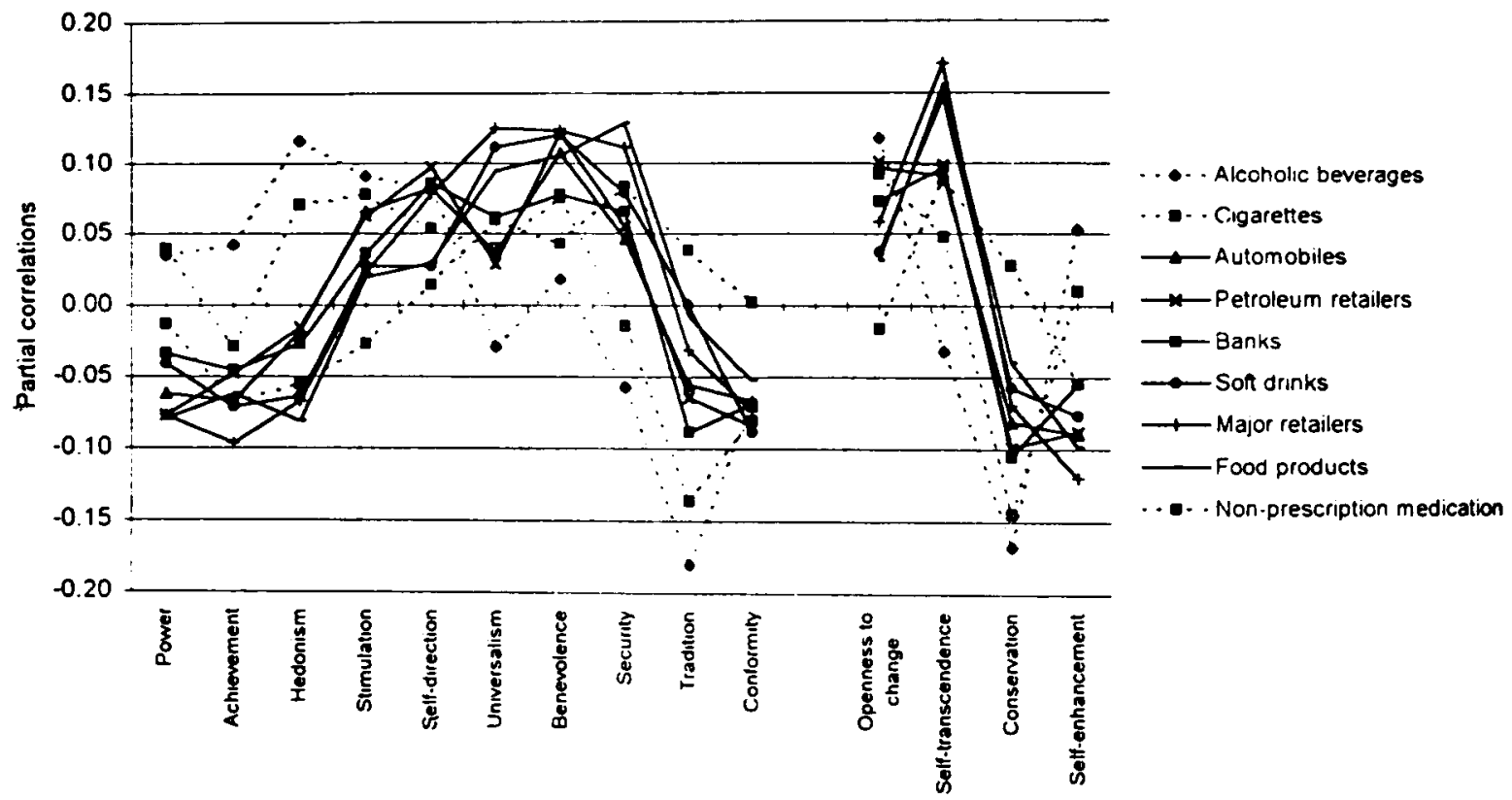

Figure 4 Correlations of reported brands ever used with value types for nine product categories partialled for mean value rating, age and household

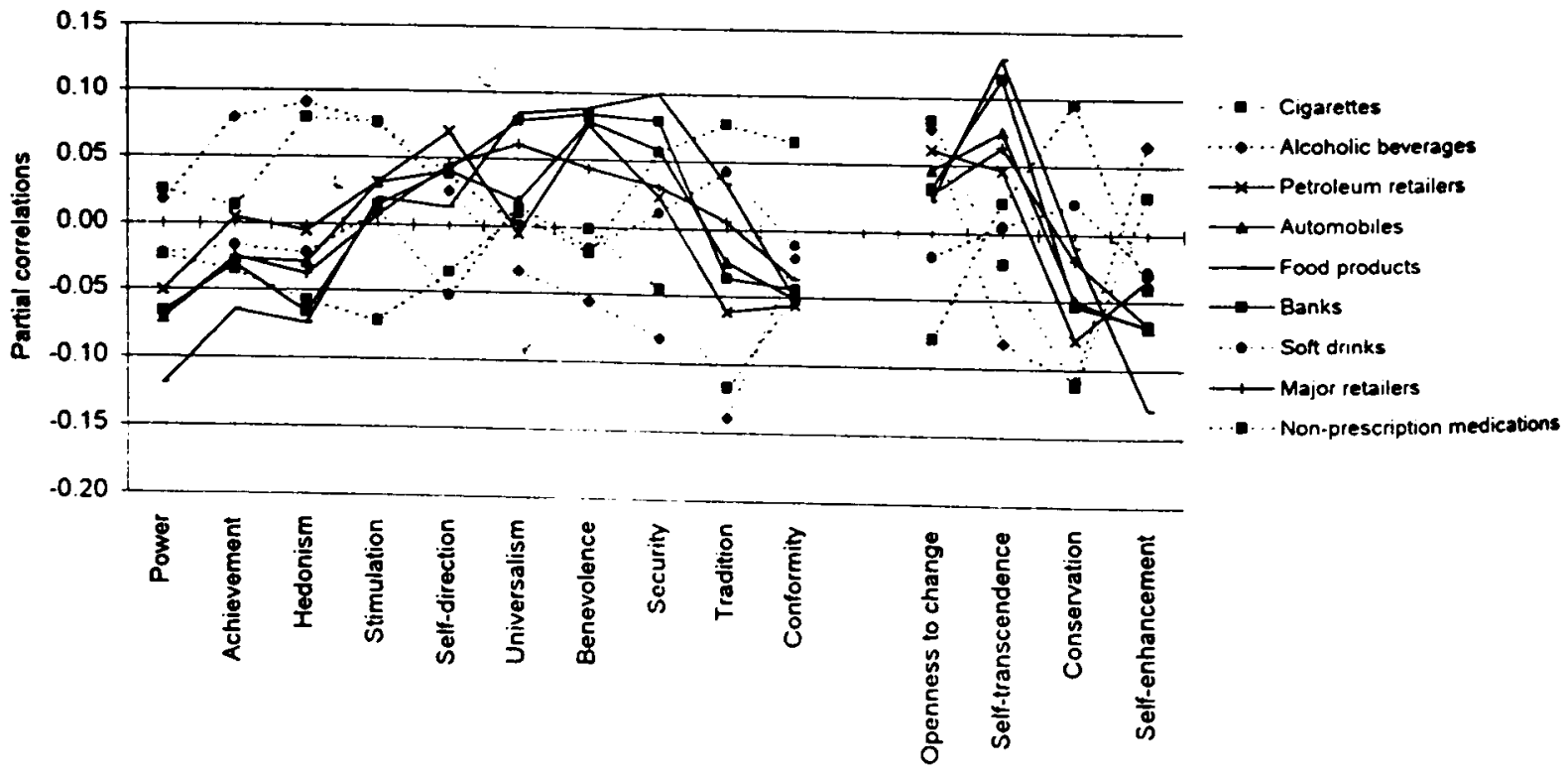
Figure 5 Correlations of reported brands regularly used now with value types for nine product categories partialled for mean value rating. agc
and houschold income 
mixed region. there is no departure from the sinusoid pattern predicted by the theory.

\section{Non-prescriptom medications.s}

Consistent with the hypothesis for this product category, a sinusoid curve emerged in which the pattern of correlations is opposed to that for alcoholic beverages and cigarettes. The highest positive correlation is with self-transcendence and conservation and the highest negative correlation is with selfenhancement and openness to change. The results are consistent for brands ever used and brands regularly used now.

\section{Banks, food products, motor cars, soft drinks and major food and clothing retailers}

The pattern of correlations between action loyalty and values for these product categories is most negative for self-enhancement and conservation values and most positive for self-transcendence and openness to change values. The same three patterns of relationships generally emerged when reported brands regularly used now were used as the indicator of brand loyalty. Ali product categories presented the same general pattern of association as with brands ever used, with one exception: the pattern of correlations for soft drinks was more consistent with predictions for non-prescription medications.

\section{Conclusions}

This study has examined the value priorities and brand loyalty of consumers with high and low stimulation preferences in nine product categories using new scales in new populations. Both new scales performed remarkably well in a difficult cross-cultural and multilingual testing environment that was characterised by literacy and numeracy deficiencies, linguistic and cultural diversity and unfavourable placement in a syndicated marketing research study. However, 'don't know' responses were concerning for both scales. The finding that high and low OSL consumers have value priorities consistent with Schwartz' value theory is important and suggests that the shortened CSI taps underlying value differences. The nomological validity of both scales is enhanced by results consistent with these theoretical expectations.

\section{Loyalty of consumers with high stimulation preferences}

As noted earlier, values and OSL have not influenced the brand loyalty literature much. The results suggest that those working in the area may wish to consider these influences. Although Models A and B more consistently identified a maximally disloyal high OSL group, Models $C$ and D produced high and low groups with significant action loyalty differences in more product categories. Models A, B and C generally identify a high user group characterised by the highest action disloyalty for alcoholic beverages, cigarettes and soft drinks. The finding concerning the OSL level and value priorities of the most disloyal Model $\mathrm{C}$ group suggests that even a limited subset of Schwartz' motivational value types may tap a much wider range of motivations; perhaps due to the interrelatedness of the value types predicted by the theory. This is highlighted by the findings concerning the model based exclusively on value system priority differences,
Model D. These findings suggest that value system differences influence brand loyalty. Each of the groups identified by Model $D$ included a broad selection of consumers from the least and most aged and wealthy strata of a society that may be among the most divided in the world. Yet, based on their value differences, Model $D$ groups exhibited the highest overall levels of loyalty and dislovalty of the four models, as well as the highest level in most individual product categories. Model D also identifies a group of loyal consumers who report highest levels of loyalty and constitute the largest number of loyal respondents produced by the four models.

Model $\mathrm{D}$ also highlights the important finding that models based on value priority differences may be sensitive to a more comprehensive set of motivations for action disloyalty. For example, the Model D Group 2 exhibits OSL levels and values consistent with the theoretical expectations for high ECB groups and this group includes the most disloyal users of the most limited problem-solving products (alcoholic beverages and cigarettes). This group may include consumers who are disloyal for reasons consistent with OSL and ECB theories. This is consistent with Sheth, Newman \& Gross (1991a). who found two main factors from the epistemic value domain that could be linked to cigarette brand switching behaviour: a desire for novelty and change and a susceptibility to persuasion by promotional communications. The highest priority on hedonism and achievement and the lowest priority on stimulation distinguish the Model D Group 3 when compared to all other models. This group exhibits the most disloyal for OTC medications and soft drinks for brands regularly used now and the highest level of action loyalty of all models in ten of the 18 product categories for total brands ever used and brands regularly used now.

When comparing Model D Group 1 and Group 3. the groups that used the most and least brands across the nine product categories for that model. Group 1 exhibits the highest lift and most significant loyalty differences between high and low groups. Group l's emphasis on conservation and self-transcendence value priorities may be somewhat surprising in light of the theoretical expectations of OSL and ECB However, this finding must be considered in the context of other pertinent points.

1. This group exhibits a relatively high degree of action loyalty in LPS product categories (especially alcoholic beverages and cigarettes) and the highest degree of disloyalty for MPS and EPS product categories.

2. The partial correlations between the value types and the two measures of action loyalty for alcoholic beverages and cigarettes exhibit a pattern of correlations to the value types similar to that of OSL.

3. While the balance of products (excepting OTC non-prescription medications) displays a pattern very similar to the mean importance of values in South African society:

4. The group's value priorities are in the direction of the average value priorities of society, but are more strongly felt

Thus, these results suggest that these respondents may not be more disloyal because of reasons traditionally associated with ECB or OSL. 


\section{OSL, values and action loyalty}

The results concerning the pattern of association between OSL, values and action lovalty suggest that value priorities and $O S I$. are related concepts that clearly influence the action loyalty of South African consumers. This is most noteworthy not only because of the findings cut across the 'developed' and 'developing' sectors of the population but also because of the nominal disparities in human development and the rapid social, political and economic change that characterise South Africa s post-apartheid transition. It would not be wise to suggest that only three patterns of association between values and brand loyalty or that the three patterns observed in the current research would be replicated in research elsewhere Nevertheless. the emergence of three patterns of association is an extremely important finding. Figure 3, which plots the rescaled mean importance ratings for the value types and the partial correlations of OSL. brands ever used and brands regularly used now. suggests that the mean priority of the value types for the entire sample and the correlations between value priorities and measures of action loyalty exhibit similar sinusoid curve patterns.

\section{Future research}

The current research contributes to our understanding of the much larger research question concerning the conceptual links between two largely separate research streams: values and personality traits. Future research should focus on three areas: (1) the shortened CSI and PQ scales, (2) the link between values and OSL. and (3) the mechanisms by which values and personality traits influence brand loyalty.

\section{I'Q and ( S S scale validation}

The current research demonstrated the utility of both new scales in a very difficult testing environment. Nevertheless, more work is required to establish the reliability and validity of the scales. The two negatively scored items of the shortened CSI are of particular concern and limit the comparability of the CSI and PQ results of the current research. One immediately wonders how the models based on the shortened CSI scale would have performed had these two items been worded positively. Previous results (Steenkamp \& Baumgartner. 1995) provided no indication of a problem with these two items and one wonders whether this is a problem related to less educated. multilingual, sub-Saharan populations. The shortened CSI seems particularly well suited for use in direct marketing and database marketing and work should proceed in this regard.

\section{lislues and OSL}

South Africans place a degree of relative importance on values much in line with pan-cultural norms (see Table 3 , Schwartz \& Bardi, 1997). With the exception of the higher degree of importance plated on power (not surprising in a country undergoing transition in power structures) and the much higher priority for security. Concerning the PQ scale. the meaning of security in the sub-Saharan region requires investigation. Does security take on a different meaning when consumers live in the challenging economic circumstances that chatacterise ECMs? What special intluence does this hase on purchase and consumption behaviour in the region, if any? The findings concerning value importance are consisten with Schwartz \& Bardi's (1997) tentative proposal conceming African countries and Fiji: that the close proximity of life in large, multigenerational, extended family households with children of different mothers, high interdependence and lack of privacy increases the requirements for successful caordination of behaviour that results in high importance for conformity and low importance for self-direction. This may well be the case in many other ECMs. Schwartz (Schwartz el al., 1992; Schwartz, 1994) reports that the spirituality motivational value type has proven unreliable across cultures. Nevertheless, spirituality is a large part of the African belief systems and its inclusion in future research may be useful. Related traditional beliefs in ECM countries, such as the African concept of ubuntu (that a person becomes a person through others), would enrich such research.

\section{Values, OSL and brand lovalty}

Although we know much about OSL, values and loyalty, we know very little about the association of these constructs or how they influence brand loyalty and the findings concerning the patterns of association in the current research will no doubt stimulate interest and new research. Schwartz' theory is an attractive organising platform for research concerning values and loyalty. The results suggest that values may be more informative concerning the motivations for disloyalty and that OSL also holds much appeal for identifying loyal and disloyal consumers. However. we urgently need to know more about how values influence all behaviour. including ECB. Alternative complementary perspectives, such as that of Bagozzi and his colleagues concerning goals (Bagozzi \& Dabholkar, 1994; 1998; Bagozzi \& Edwards, 1996: Bagozzi \& Kimmel, 1995), should be encouraged.

Work also should proceed concerning the interrelationship of values and valences. Although Sheth, Newman \& Gross' (199lb) theory of consumpion values has attracted little interest, it suggests an important consideration for understanding how valences influence purchase and consumption behaviour that should be investigated. The results here suggest that consumer perceptions of hedonic and utilitarian brand benefits also may be an important influence requiring greater exploration. Problem-solving and involvement appear to be other possible influences that should be considered. Fi nally, we need to understand the mechanism by which values and personality traits influence brand loyalty at the various developmental stages of consumer relationships with brands.

This research has reviewed the links between the OSL and values literature, demonstrated an alternative method of identifying brand loyal consumers based on value priorities and shown interesting patterns of association between value priorities and different types of products. The results suggest that researchers and applied marketers should consider both concepts when developing research or managerial strategies concerning brand loyalty. Future research will no doubt show even greater benefits from this approach.

\section{Notes}

1. The concept of stibjective value that informs some theortical perspectives on hrand losalts and relationship marketing (c.g Jïttner \& Wehrli. 199.4. (Oliver. 1997: /eithaml. 1988) differs 
from the personal talues concept appliced in the currem research (sce Burgess. 1992: leather. 1995) It is important to establish the difference between two momportant ly pes of values: the subectire value concept that intorms many conomic and consume behaviour theories and the human values concept more often employed in psichological and consumer rescarch. Exemplar of the former is Sheth. New man \& (iross (1991a: 1991b) theory of consumption values in which live $t y$ pes of values influence consumer purchase and comsumption decisions. For example. choosing one of these five values. Sheth et al $(1991 \mathrm{~b})$ argue tha the genesis of exploratory. Iariety-seeking and novelty-seeking behaviours often can be traced to the desire for epistemic value They suggest that consumers derive epistemic value from the capacity of a purchase or consumption experience to provide novelty or to arouse curiosity or knowledge-seeking aspirations and note that unfamiliar and somewhat ambiguous or complex stimuli often enhance epistemic value of a purchase or consumption experience. Sheth et al s theory calls attention to a range of underlying dimensions of attraction that may be active when consumers evaluate perceived utility during purchase and consumption behaviour. These subjective values are related but very different to the human values concept investigated in the curren research. Lluman values are transituational goals that transcend objects or events. Keeping with recent attempts to avoid confusion between these two values concepts (i.e. Feather, 1995), subjective values are referred to as valences in the current research. Valence. a recurring concept in the work of Lewin (1951). refers to the subjective attraction or aversion to an object or event within an immediate situation.

2. We are aware that this classitication differs from traditional classitication in overseas texthooks. Banks and motor cars probably are examples of mid-range problem solving (MPS) in South Africa due to the small amount of differentiation in the product offerings of the major four bank groups and the prevalence of car allowance and company car schemes that lower the perceived real cost of an automobile for many consumers. Food product brands were considered to he MPS products because of the relative price of pre-packaged foods in the context of the constrained economic resources that characterise most South African consumer lifestyles.

3. Reliabilities for the four traditional ethnic groups for the shortened CSl were Asians, .8851: Blacks, .8095: Coloureds, .8803. Whites. 8720 .

4. Burgess \& Steenkamp (1998) report detailed information concerning the value antecedents and also participation in a set of innovative product categories from the current research.

5. Reliabilities for the four traditional ethnic groups for the PQ were Asians, .8841, .5408, .5208, .8453: Blacks, .7261, .5205. $.5801, .7659$; Coloureds, .8341, .5578, .7621, .8153, Whites, $.7996, .6307, .6878, .8280$ ): for openness to change. conservation. self-enhancement and self-transcendence, respectively.

6. It is important to note that respondents from the lower strata reported brand disloyalty in eategories in which one might expect them to be economically able to purchase and try many brands, such as soft drinks. As part of the initial examination of the results, we identified lower-income respondents who claimed high product usage. The results were encouraging concerning the validity of the self-reports. When the higher economic value EPS product categories were examined, up to $97 \%$ of these respondents reported using none of the brands regularly and $89 \%$ to have never used any of the brands. Even in more affordable product categories. more than $50 \%$ claimed to use no alcoholic beverages or cigarette brands and $20 \%$ claimed to not use any of the major retail food and clothing chain brands.

\section{Acknowledgement}

This research was supported by a grant from Markinor (Ply) I.td. and by the Association of Marketers (hair of Marketing He gratefully thank Markinor CFO Sue Grant for her support: Shalom Schwartz for use of his Portraits Questionnaire advice and initial analysis concerning reliability: and JanBenedict E.M. Steenkamp and Richard Bagozzi for comments that improved an earlier draft manuscript.

\section{References}

Bagozzi, R.P. \& Dabholkar. P.A. 1994 Consumer recu cling goals and their effectron decisions to recycle: a means-end chain anal. sis. Psychology \& Marketing. 11: 313-340.

Bagozzi, R.P. \& Dabholkar. P.A. 1998. (ognitive schemas and means-end chain theon: application to the marketing of political candidates (Working paper). Ann Arbor. Michigan: University of Michigan.

Bagozzi. R.P., Dabholkar. P.A. \& Edwards. E.A. 1996. (ioal Settmg and Goal Pursuit in the Regulation of Bodv Weight (llorking Paper). Ann Arbor. Michigan: University of Michigan.

Bagozzi. R.P. \& Dabholkar. P.A. 1998. A general approach for representing constructs in organizational research. Organizarional Research Methods, I(1): 45-87

Bagozzi, R.P., Dabholkar. P.A. \& Kimmel. S.K. 1995. A comparison of leading theories for the prediction of goal-directed hehaviors. British Journal of Social Psichologv. 34: 437-461

Bagozzi, R.P.. Dabholkar. P.A. \& Warshaw. P.R. 1990. Irying to consume. Journal of Consumer Research. 17: 127-141)

Baumgartner. H. \& Steenkamp. J.-B.E.M 1996 Exploratory consumer behaviour: conceptualization and measurement. International Journal of Research in Marketing. 13(2): 121-137.

Berlyne. D.E. 1960. Conflict, arousal and curiosity. New York: McGraw-Hill.

Berry, L.L. 1995. Relationship marketing of services: grow ing interest, emerging perspectives, Journal of the Academl of 1/arketing Science. 23(4): 236-245.

Berry, L.L. \& Gresham. L.G. 1986. Relationship retailing: transforming customers into clients. Business Horizons. Now/ Dec. 43-47.

Berry. M.J.A., \& Linoff, G. 1997. Data mining techniques for marketing, sales, and customer support. New York: Wile!

Bilsky. W.. \& Schwartz. S. H. 1994. Values and personality. European Journal of Psychology. 8: 163-181.

Blattberg, R.C., \& Deighton. J. 1991. Interactive marketing: exploiting the age of addressability. Sloan .Management Review; (Fall): 5-14.

Bollen, K.A. 1989. Structural equations with latent variables. New York: Wiley.

Brislin, R.W. 1986. The wording and translation of research instruments. In Lonner, W.J. \& Berry. J.W. eds. Field methods in crosscultural research (Vol. 8: 137-164). Beverly Hills. California: Sage.

Brislin, R.W., Lonner, W.J. \& Thorndike. R.M. 1973. Cross-cultural research methods. New York: Wiley

Burgess, S.M. 1992. Personal valies and consumer research: an historical perspective. In Sheth. J.N. ed. Research in Marketing (Vol. 11: 35-80). Greenwich. Connecticut: JAl Press.

Burgess, S.M. 1998. The new marketing: building strong marketing strategies in South Africa today. Johannesburg: Zebra Press - a division of New Holland Struik Publishing Group (Pty) Ltd.

Burgess. S.M., Schwartz. S.H. \& Blackwell. R.D. 1994. Do values share universal content and structure?' A South African test. South African Journal of Psychologv. 24(1): 1-12.

Burgess, S.M. \& Steenkamp. J.-B.E.M. 1998. Value priorities and consumer behavior in a transitional economy: the case of South 


\section{OSL, values and action loyalty}

The results concerning the pattern of association between OSL. values and action loyalty suggest that value priorities and $O S L$ are related concepts that clearly influence the action lovalty of South African consumers. This is most noteworthy not only because of the findings cut across the developed' and 'developing" sectors of the population but also because of the nominal disparities in human development and the rapid social, political and economic change that characterise South Africa s post-apartheid transition. It would not be wise to suggest that only three patterns of association between values and brand loyalty or that the three patterns observed in the current research would be replicated in research elsewhere. Nevertheless, the emergence of three patterns of association is an extremely important finding. Figure 3, which plots the rescaled mean importance ratings for the value types and the partial correlations of OSL. brands ever used and brands regularly used now. suggests that the mean priority of the value types for the entire sample and the correlations between value priorities and measures of action loyalty exhibit similar sinusoid curve patterns.

\section{Future research}

The current research contributes to our understanding of the much larger research question concerning the conceptual links between two largely separate research streams: values and personality traits. Future research should focus on three areas: (1) the shortened CSI and PQ scales, (2) the link berween values and OSL. and (3) the mechanisms by which values and personality traits influence brand loyalty

\section{IO and C ST scale rutidation}

The current research demonstrated the utility of both new scales in a very difficult testing environment. Nevertheless, more work is required to establish the reliability and validity of the scales. The two negatively scored items of the shortened $\mathrm{CSl}$ are of particular concern and limit the comparability of the $\mathrm{CSI}$ and $\mathrm{PQ}$ results of the current research. One immediately wonders how the models based on the shortened CSI scale would have performed had these two items been worded positively. Previous results (Steenkamp \& Baumgartner. 1995) provided no indication of a problem with these two items and one wonders whether this is a problem related to less educated. multilingual. sub-Saharan populations. The shortened CSI seems particularly well suited for use in direct marketing and database marketing and work should proceed in this regard

\section{lalues and OSL}

South Africans place a degree of relative importance on values much in line with pan-cultural norms (see Table 3 . Schwartz \& Bardi, 1997). "wh the exception of the higher desree of importance placed on power (not surprising in a country undergoing transition in power structures) and the much higher priority for security. Concerning the PQ scale. the meaning of security in the sub-Saharan region requires intestigation. Does security take on a different meaning when consumers live in the challenging economic circumstances that characterise EC Ms". Wat special intluence does this hate on purchase and consumption behaviour in the region, if any? The findings concerning value importance are consistent with Schwartz \& Bardi's (1997) tentative proposal concerning African countries and Fiji: that the close proximity of life in large, multigenerational, extended family households with children of different mothers, high interdependence and lack of privacy increases the requirements for successful coordination of behaviour that results in high importance for conformity and low importance for self-direction. This may well be the case in many other ECMs. Schwartz (Schwartz et al., 1992; Schwartz, 1994) reports that the spirituality motivational value type has proven unreliable across cultures. Nevertheless, spirituality is a large part of the African belief systems and its inclusion in future research may be useful. Related traditional beliefs in ECM countries, such as the African concept of ubuntu (that a person becomes a person through others), would enrich such research.

\section{Values, OSL and brand loyalty}

Although we know much about OSL, values and loyalty, we know very little about the association of these constructs or how they influence brand loyalty and the findings concerning the patterns of association in the current research will no doubt stimulate interest and new research. Schwartz' theory is an attractive organising platform tor research concerning values and loyalty. The results suggest that values may be more informative concerning the motivations for disloyalty and that OSL also holds much appeal for identifying loyal and disloyal consumers. However. we urgently need to know more about how values influence all behaviour, including ECB. Alternative complementary perspectives, such as that of Bagozzi and his colleagues concerning goals (Bagozzi \& Dabholkar, 1994; 1998; Bagozzi \& Edwards, 1996; Bagozzi \& Kimmel, 1995), should be encouraged.

Work also should proceed concerning the interrelationship of values and valences. Although Sheth, Newman \& Gross (1991b) theory of consumpion values has attracted little interest, it suggests an important consideration for understanding how valences influence purchase and consumption behaviour that should be investigated. The results here suggest that consumer perceptions of hedonic and utilitarian brand benefits also may be an important influence requiring greater exploration. Problem-solving and involvement appear to be other possible influences that should be considered. Finally, we need to understand the mechanism by which values and personality traits influence brand loyalty at the various developmental stages of consumer relationships with brands.

This research has reviewed the links between the OSL and values literature, demonstrated an alternative method of identifying brand loyal consumers based on value priorities and shown interesting patterns of association between value priorities and different types of products. The results suggest that researchers and applied marketers should consider both concepts when developing research or managerial strategies concerning brand loyalty. Future research will no doubt show even greater benefits from this approach.

\section{Notes}

1. The concept of subjective value that informs some theoretical perspectives on hrand towalt! and relationship marketing (e.g. Jütner \& Wehrli. 199.4: ()lice. 1997: \%eithaml. 1988) differs 
trom the personal balaces concept applied un the current rescarch

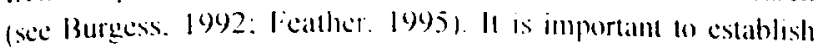
the difference between $1 w 0$ mprortant I! pes of values: the subjective value concept that intorms many economic and consumer hellaviour theorics and the humam values concept more often employed in psichological and consumer rescarch. Exemplary of the former is Sheth. Newman \& (iross (1991a: 1991b) theory of consumption values in which tice types of values influence consumer purchasc and consumption decisions. For example. choosing onc of these five values. Sheth ef al (199/b) argue that the genesis of exploratory. I ariety-secking and novelty-seeking behaviours often can be traced to the desire for epistemic value. They suggest that consumers derive epistemic value from the capacity of a purchase or consumption experience to provide novelty or to arouse curiosity or knowledge-seeking aspirations and note that unfamiliar and somewhat ambiguous or complex stimuli often enhance epistemic value of a purchase or consumption experience. Sheth et al 's theory calls attention to a range of underlying dimensions of attraction that may be active when consumers evaluate perceived utility during purchase and consumption behaviour. These subjective values are related but very different to the human value's concept investigated in the current research. Human values are transituational goals that transcend objects or events. Keeping with recent attempts to avoid confusion between these two values concepts (i.e. Feather, 1995), subjective values are referred to as valences in the current research. Valence, a recurring concept in the work of Lewin (1951), refers to the subjective attraction or aversion to an object or event within an immediate situation

2. We are aw are that this classitication differs from traditional classification in overseas textbooks. Banks and motor cars probably. are examples of mid-range problem solving (MPS) in South Atrica due to the small amount of differentiation in the product offerings of the major four bank groups and the prevalence of car allowance and company car schemes that lower the perceived real cost of an automobile for many consumers. Food product brands were considered to be MPS products because of the relative price of pre-packaged foods in the context of the constrained economic resources that characterisc most South African consumer lifestyles.

3. Reliabilities for the four traditional ethnic groups for the shortened CSI were Asians, .8851: Blacks, .8095: Coloureds. .8803, Whites. 8720 .

4. Burgess \& Steenkamp (1998) report detailed information concerning the value antecedents and also participation in a set of innovative product categories from the current research.

5. Reliabilities for the four traditional ethnic groups for the PQ were Asians, .8841, .5408. .5208, .8453: Blacks, .7261, .5205. $.5801, .7659$; Coloureds, .8341, .5578, .7621, .8153, Whites, $.7996, .6307 . .6878, .8280$ : for openness to change. conservation. self-enhancement and self-transcendence. respectively.

6. It is important to note that respondents from the lower strata reported brand disloyalty in categories in which one might expect them to be economically able to purchase and try many brands, such as soft drinks. As part of the initial examination of the results, we identified lower-income respondents who claimed high product usage. The results were encouraging concerning the validity of the self-reports. When the higher economic value EPS product categories were examined, up to $97 \%$ of these respondents reported using none of the brands regularly and $89 \%$ to have never used any of the brands. Even in more affordable product categories, more than $50 \%$ claimed to use no alcoholic beverages or cigarette brands and $20 \%$ claimed to not use any of the major retail food and clothing chain brands.

\section{Acknowledgement}

This research was supported by a grant from Markinor (P1!) Ltd and by the Association of Marketers (hair of Marketing We gratefully thank Markinor CEO Sue Grant for her support: Shalom Schwartz for use of his Portraits Questionnaire. advice and initial analysis concerning reliability: and lanBenedict E.M. Steenkainp and Richard Bagozzi for comments that improved an earlier draft manuscript.

\section{References}

Bagozzi. R.P. \& Dabholkar. P.A. 1994 (Consumer reçcling goals and their effecton decisions to recycle: a means-end chain anal! sis. Psychology \& Marketing. 11: 313-340)

Bagozzi. R.P. \& Dabholkar. P.A. 1998. ('ognitive schemas and means-end chain theon: application to the marketing of political candidates (Working paper). Ann Arbor. Michigan: I niversity of Michigan.

Bagozzi. R.P., Dabholkar. P.A. \& Edwards. E.A. 1996. Goal Setling and Goal Pursuit in the Regulation of Body Weight (Working Paper). Ann Arbor. Michigan: (University of Michigan

Bagozzi. R.P. \& Dabholkar. P.A. 1998. A general approach for representing constructs in organizational research. Organizational $R_{e}$ search Methods, I(1): 45-87.

Bagozzi, R.P.. Dabholkar. P.A. \& Kimmel. S.K. 1995. A comparison of leading theories for the prediction of goal-directed behaviors. British Journal of Social Psvcholngv. 34: 437-461

Bagozzi, R.P.. Dabholkar. P.A. \& Warshaw. P.R. 1990. Trying to consume. Journal of Consumer Research. 17: 127-1411.

Baumgartner. H. \& Steenkamp. J.-B.E.M. 1996. Exploratory consumer behaviour: conceptualization and measurement. International Journal of Research in Marketing. 13(2): 121-137.

Berlyne. D.E. 1960. Conflict, arousal and curiosity. New York: McGraw-Hill.

Berry. L.L. 1995. Relationship marketing of services: grow ing interest, emerging perspectives. Journal of the Academy of I/arketing Science. 23(4): 236-245.

Berry, L.L. \& Gresham. L.G. 1986. Relationship retailing: transforming customers into clients. Business Horizons. Nov / Dec. 43-47.

Berry. M.J A., \& Linoff, G. 1997. Data mining techniques for marketing, sales, and customer support. New York: Wile!

Bilsky, W.. \& Schwartz. S. H. 1994 . Values and personality. European Journal of Psychologv. 8: 163-181.

Blattberg. R.C., \& Deighton. J. 1991. Interactive marketing: exploiting the age of addressability. Sloan . Ianagement Rewew. (Fall) 5-14.

Bollen, K.A. 1989. Structural equations with latent variables. New York: Wiley.

Brislin, R.W. 1986. The wording and translation of research instruments. In Lonner. W.J. \& Berry. J.W. eds. Field methods in crosscultural research (Vol. 8: 137-164). Beverly Hills. California: Sage.

Brislin, R.W., Lonner, W.J. \& Thorndike. R.M. 1973. Cross-cultural research methods. New York: Wiley

Burgess, S.M. 1992. Personal values and consumer research: an historical perspective. In Sheth. J.N. ed. Research in Marketing (Vol. 11: 35-80). Greenwich. Connecticut: JAl Press.

Burgess, S.M. 1998. The new marketing: building strong marketing strategies in South Africa today: Johannesburg: Zebra Press - a division of New Holland Struik Publishing Group (Pty) Ltd

Burgess. S.M. Schwartz. S.H. \& Blackwell. R.D. 1994. Do values share universal content and structure?. A South African test. South African Journal of Psychologv. 24(1): $1-12$

Burgess, S.M. \& Steenkamp. J.-B.E.M. 1998. Valuc priorities and consumer behavior in a transitional economy: the case of South 
Africa Paper presented at the Marketing in Transitional Economies Conference. Ann Arbor, Michigan: William H. Davidson Institute. University of Michigan

Cravens, D.W. 1995. Special issue on relationship marketing, Journal of the Academy of Marketing Science, 23(4)

Cross, R. \& Smith, J. 1995. Customer bonding: pathway to lasting customer loyalty. Lincolnwood. Illinois: NTC Business Books.

Cunningham. W.H. \& Green. R.T. 1984. From the editor, Journal of Marketing. 48: 9-10.

Dick, A.S. \& Basu. K. 1994. Customer loyalty: toward an integrated conceptual framework, Journal of the Academy of Marketing Science, 22(2): 99-13.

Duda, R.O. \& Hart. P.E. 1973. Pattern classification and scene analysis. New York: John Wiley.

Engel, J.F.. Blackwell, R.D. \& Miniard. P.W. 1995. Consumer behavior. 8th edition ed. Fort Worth: Dryden.

Feather, N.T. 1995. Values, valences, and choice: the influence of values on the perceived attractiveness and choice of alternatives, Journal of Personality and Psychology, 68(6): 1135-1151.

Fiske, D.W. \& Maddi, S.R. 1961 . Function of varied experience. Homewood. Illinois: The Dorsey Press.

Fournier, S. \& Yao, J.L. 1997. Reviving brand loyalty: a reconceptualization within the framework of consumer-brand relationships, International Journal of Research in Marketing, 14(5): 451-472.

Fowler, H. 1965. Curiosity and exploratory behavior. New York: MacMillan.

Garlington. W'K.. \& Shimota. H.E. 1964. The change seeker index, Psychological Reports, 14: 919-924.

Hansen, F. 1972. Consumer choice behavior: a cognitive theory. New York: Free Press.

Hebb, D.O. 1955. Drives and the C.N.S (Central Nervous System), Psychological Review. 62: 243-254.

Hirschman. E.C. 1980. Innovativeness, novelty seeking, and consumer creativity, Journal of Consumer Research, 7: 283-295.

Hirschman. E.C. 1984. Experience seeking: a subjectivist perspective of consumption. Journal of Business Research, 12: 115-136.

Hirschman. E.C. \& Holbrook, M.B. 1982. Hedonic consumption: emerging concepts. methods and propositions, Journal of Marketing. 46: 115-136.

Holbrook. M.B. \& Hirschman, E.C. 1982. The experiential aspects of consumption: consumer fantasies. feelings and fun, Journal of Consumer Research. 9: 132-140.

Holyoake, E.T. \& Gordon, P.C. 1983 . Social reference points, Journal of Personality and Social Psychology, 44: 881-887.

Howard, J.A. \& Sheth, J.N. 1969. The theory of buyer behavior. New York: Wiley.

Hunt, S.D. \& Morgan, R.M. 1994. Relationship marketing in the era of network competiton, Marketing Management, 3(1): 19-28.

Jüttner, U. \& Wehrli, H.P. 1994. Relationship marketing from a value system perspective, International Journal of Service Industry Management. 5(5): 54-73.

Kahle, L.R. 1990. Contemperary research on consumer and business social values. Journal of Business Research. 20(2): 81-82.

Kahle, L.R. \& Timmer. S.G. 1984. A theory and á method for studying values. In Kahle, L.R. ed. Social values and social change: adaptation to life in America. New York: Praeger, pp. 43-72.

Krishnamurthi. L. \& Raj, S.P. 1991. An empirical analysis of the relationship between brand loyaliy and consumer price elasticities, Marketing Science, 10(2): 172-183.

Laurent. G. \& Kapferer. J.-N. 1986). Consumer involvement profiles: a new practical approach to consumer involvement, Journal of Advertising Research, 25: 49-56.

Leuba. C. 1955. Toward some integration of learning theories: the concept of optimum stimulation. Psychological Reports, 1: 27-33

Lewin. K. ed. 1951. Field theorv in social science: selected theoretical papers. New York: Harper.
Lonner, W.J. \& Berry, J.W. eds. 1986. Field methods in cross-cultural research. (Vol. 8). Beverly Hills, California: Sage.

Maddi, S.R. 1961. Exploratory behavior and variety seeking in man. In Fiske, D.W. \& Maddi, S.R. eds. Functions of varied experience. Homewood, Illinois: Dorsey Press, pp. 253-277.

McAlister, L. \& Pessemier, E.A. 1982. Variety seeking behavior: an interdisciplinary review, Journal of Consumer Research, 9: 311322.

Mehrabian, A. \& Russell, J.A. 1974. An approach to environmental psychology. Cambridge, Mass.: MIT Press.

Milligan, G.W. 1981. A review of Monte Carlo tests of cluster analy. sis, Multivariate Behavioral Research, 16: 379-407.

Milligan, G.W. \& Cooper, M.C. 1987. Methodology review: clustering methods, Applied Psychological Measurement. 11(4): 329 354.

Monroe, K.B. 1993. Editorial, Journal of Consumer Research, 19 (March).

Oliver, R.L. 1997. Satisfaction: a behavioral perspective on the customer. New York: McGraw-Hill

Payne, A. 1995. Relationship marketing: a broadened view of marketing. In Payne, A. ed. Advances in relationship marketing. London: Kogan Page, pp. 29-40.

Peppers, D. \& Rogers, M. 1993. The one to one future: building business relationships one customer at a time. London: Piatkus.

Peppers, D. \& Rogers, M. 1997. Enterprise one to one future: tools for building unbreakable customer relationships in the interactive age. London: Piatkus.

Pitts, R.E. \& Woodside, A.G. 1984. Personal values and consumer psychology. Lexington, Massachusetts: Lexington Books.

Quelch. J.A. \& Austin, J.E. 1993. Should multinationals invest in Africa? Sloan Management Review. (Spring): 107-119.

Raju, P.S. 1980. Optimum stimulation level: its relationship to personality, demographics, and exploratory behavior, Journal of Con sumer Research, 7: 272-282.

Raju, P.S. 1981. Theories of exploratory behavior: review and consumer research implications. In Sheth, J.N. ed. Research in Marketing. (Vol. 4: 223-249). Greenwich, Connecticut: JAI Press.

Reichheld, F.F. 1996. The loyalty effect: the hidden force behind growth, profits and lasting value. Boston: Harvard Business School.

Richins, M. L. \& Dawson, S. 1992. A consumer values orientation for materialism and its measurement: scale development and validation, Journal of Consumer Research, 19: 303-316.

Rokeach, M. 1973. The nature of human values. New York: Free Press.

Schwartz, S.H., Roccas, S. \& Sagiv, L. 1992. Universals in the content and structure of values: theoretical advances and empirical tests in 20 countries, Advances in Social Psychology, 25.

Schwartz, S.H. 1994. Are there universal aspects in the content and structure of human values? Journal of Social Issues, 50: 19-45.

Schwartz, S.H. 1996. Value priorities and behavior: applying a theory of integrated value systems. In Seligman, C. Olson, J.M. \& Zanna, M.P. eds. The psychology of values: the Ontario Symposium (Vol. 8). Hillsdale, New Jersey: Lawrence Erlbaum.

Schwartz. S.H. \& Bardi, A. 1997. Cross-cultural similarities in value hierarchies: evidence and implications (Working Paper). Jerusalem: Hebrew University of Jerusalem.

Schwartz, S.H., Lehmann, A.. Melech, G.. Burgess, S.M. \& Harris, M. 1998. Validation of a theory of basic human values with a new instrument in new populations (Working Paper). Jerusalem: Hebrew University of Jerusalem.

Schwartz, S.H., Lehmann, A. \& Roccas, S. (in press). Multimethod probes of basic human values. In Adamopoulos. J. \& Kashima. $Y$ eds. Social psychology and cultural context. Newbury Park. California: Sage.

Schwartz, S.H., Verkasalo, M., Anotovsky. A. \& Sagiv, L. 1997. 
Value priorities and social desirability: much substance. some style, British Journal of Social Psychology, 36(1):3-18

Sheth, J.N.. Newman, B.I. \& Ciross. B.L. 1991 la. Consumption values and market choices: theory and applications. Cincinnatti. Ohio: South-Western Publishing.

Sheth, J.N.. Newman, B.I., \& Gross, B.L. 1991b. Why we buy what we buy: a theory of consumption values. Journal of Business Research, 22: 159-170.

Sheth, J.N. \& Parvatiyar, A. 1995. Relationship marketing in consumer markets: antecedents and consequences, Journal of the Academy of Marketing Science, 23(4): 255-271.

Srull, T.K. \& Gaelik, L. 1983. General principles and individual differences in the self as a habitual reference point: an examination of self-other judgements of similarity, Social Cognition, 2: 108121.

Steenkamp. J.-B.E.M. \& Baumgartner, H. 1992. The role of optimum stimulation level in exploratory consumer behavior, Journal of Consumer Research, 19: 434-448.

Steenkamp, J.-B.E.M. \& Baumgartner, H. 1995. Development and cross-cultural validation of a short form CSI as a measure of optimum stimulation level, International Journal of Research in Marketing, 12(2): 97-104.

Steenkamp, J.-B.E.M. \& Baumgartner, H. (in press). Assessing measurement invariance in cross-national consumer research Journal of Consumer Research.

Steenkamp. J.-B.E.M. \& Baumgartner, H. \& Van der Wulp, E. 1996. The relationships among arousal potential, arousal and stimulus evaluation. and the moderating role of need for stimulation. International Journal of Research in Marketing, 13(4): 319-329.

Steenkamp, J.-B.E.M., Ter Hofstede, F. \& Wedel, M. (in press). A cross-national investigation into the individual and cultural antecedents of consumer innovativeness, Journal of Marketing.

Tapscott, D. 1996. The digital economy: promise and peril in the age of networked intelligence. New York: McGraw-Hill.

Tversky, A. 1977. Features of similarity, Psychological Review, 84: 327-352.

Venkatesan, M. 1973. Cognitive consistency and novelty seeking. In Ward, S. \& Robertson, T.S. eds. Consumer behavior: theoretical sources. Englewood Cliffs, New Jersey: Prentice-Hall.

Zeithaml, V.A. 1988. Consumer perceptions of price, quality and value: a means-end model and synthesis of evidence, Journal of Marketing, 52: 2-21.

Zuckerman. M. 1979. Sensation seeking: beyond the optimal level of arousal. Hinsdale, New Jersey: Lawrence Erlbaum.

\section{Appendix: Portraits questionnaire instructions and items (male form)}

Describe some people. Please read each description and think about how much each person is or is not $X$ in the box to the right that shows how much the person in the description is like you."

It is important to him to be polite to other people all the time. He believes he should always show respect to his parents and to older people. (Conformity)

Thinking up new ideas and being creative is important to him. He likes to do things in his own original way. (Self-direction) Being very successful is important to him. He likes to stand out and to impress other people. (Achievement)

He thinks it is important to do things the way he learned from his family. He wants to follow their customs and traditions. (Tradition)

He thinks it is important that every person in the world should be treated equally. He wants justice for everybody, even for people he doesn't know. (Universalism)
He likes surprises and is always looking for new things to do. He thinks it is important to do lots of different things in his life. (Stimulation)

The safety of his country is very important to him. He wants his country to be safe from its enemies. (Security)

He always wants to help the people who are close to him. It's very important to him to care for the people he knows and likes. (Benevolence)

He likes to be in charge and tell others what to do. He wants people to do what he says. (Power)

He really wants to enjoy life. Having a good time is very important to him. (Hedonism)

He likes to make his own decisions about what he does. It is important to him to be free to plan and to choose his activities for himself. (Self-direction)

He thinks it's important not to ask for more than what you have. He believes that people should be satisfied with what they have. (Tradition)

It's important to him to be rich. He wants to have a lot of money and expensive things. (Power)

He looks for adventures and likes to take risks. He wants to have an exciting life. (Stimulation)

Honesty is very importnat to him. He believes he must be honest in any situation and always tell the truth. (Benevolence)

It is important to him that everything is clean and in order. He really doesn't want things to be a mess. (Security)

He looks for every chance he can to have fun. It is important to him to do things that give him pleasure. (Hedonism)

He strongly believes that people should care for nature. Looking after the environment is important to him. (Universalism)

He believes that people should do what they're told. He thinks people should follow rules at all times, even when noone is watching. (Conformity)

He likes people to know that he can do well. He is ambitious and ready to work hard to get ahead. (Achievement)

His family's safety is extremely important to him. He would do anything to make sure his family is always safe. (Security) It's important to him to listen to people who are different from him. Even when he disagrees with them, he still wants to understand them and to get along with them. (Universalism)

He doesn't like to boast or draw attention to the things he does. He wants to be modest. (Tradition)

$\mathrm{He}$ thinks it's important to be interested in things. He is curious and tries to understand everything. (Self-direction)

It is important to him to fit in and do things the way other people do. He thinks he should do what others expect of him. (Conformity)

He thinks everyone should work to get people in the world to live together peacefully. Peace everywhere in the world is important to him. (Universalism)

It is very important to him to show his abilities. He wants people to admire what he does. (Achievement)

It is important to him that his friends can always trust him. He wants to be loyal to them and always look out for their interests. (Benevolence)

Being religious is important to him. He tries hard to follow his religious beliefs. (Tradition) 